\title{
Investigation of Structural Response of Reinforced Concrete Beams Strengthened with Anchored FRPs
}

\author{
Constantinos B. Demakos ${ }^{*}$, Constantinos C. Repapis and Dimitrios Drivas
}

Department of Civil Engineering, Technological Education Institute of Piraeus, 250 Thivon and Petrou Ralli Str., Aigaleo 122 44, Athens, Greece

\begin{abstract}
The beneficial effect of a composite material anchorage system (CMAS) upon the ductility and load capacity of reinforced concrete (RC) beams strengthened either with glass (GFRP) or carbon (CFRP) fabrics was investigated. The anchorage system consisted of U-shaped GFRP or CFRP strip (U-strip) at end of FRP. The U-strips were bonded around the beam section and further anchored by two tufts of glass fibres, each of them embedded at the opposite beam face and specifically in the region of compression zone of the beam web. Experimental evaluations in simply supported lightly reinforced concrete (RC) beams strengthened with one GFRP or a CFRP sheet anchored at its ends by the composite anchorage have shown that their bending capacity has increased by $8 \%$ and $17 \%$, respectively, in relation to the capacity attained in similar RC strengthened beams without anchorage. On the other hand, their ductility was improved by an amount of $94 \%$ and $37 \%$, respectively.

ANSYS finite element program was also used to numerically verify the response of strengthened RC beams obtained experimentally. The numerical results obtained are in good agreement with the experimental, thus, the calibrated model could now be used to extend the experimental results at lower cost.
\end{abstract}

Keywords: Anchored FRP, ANSYS, experiment, finite element model, numerical modelling, reinforced concrete beam.

\section{INTRODUCTION}

The need to strengthen RC structures is encountered in cases of load increase or damage induced to the structural members by a seismic or other action and in cases of design and construction faults. Various techniques can be applied to overcome such a structural deficiency resulting in a partial repair or complete replacement of the structure damaged. The use of FRP materials for structural repairing presents several advantages [1-6], such as the high strength to weight ratio of FRP, the ease of FRPs application on site due to little equipment needed and finally the improved durability and corrosion resistance in strengthened structures. Externally bonded FRP laminates and fabrics can be used to increase shear and flexural strength of reinforced beams and columns. In order to increase flexural strength of beams, a continuous sheet of FRP can be bonded at its bottom face.

The structural behavior of flexural members with bonded FRPs as external reinforcement has been extensively investigated [7-12]. In all these studies, the lack of an effective anchorage of the composite plate reinforcing the RC member results in loss of the flexural design capacity of the member. Thus, new efforts have been devoted to an easy application of FRP anchorage, which will result in as much as possible increase of the load carrying capacity and ductility of strengthened RC beams. By decreasing the thickness and increasing bonded length of FRP sheets, a shear-type crack

*Address correspondence to this author at the Department of Civil Engineering, Technological Education Institute of Piraeus, 250 Thivon and Petrou Ralli Str., Aigaleo 122 44, Athens, Greece;

Tel: +30 210538 1558; Email: cdem@ teipir.gr pattern developed along the beam can be modified to a flexural one. However, the effectiveness of the FRP strengthening is reduced due to the likelihood of debonding at strains considerably lower than the strain capacity of the FRP. Further studies [13] have shown that properly designed external anchorages of FRP sheets applied to RC beams can lead to increase of the load capacity accompanied with substantial regain of the beam's lost structural ductility. Specifically, it has been shown that the CFRP post-strengthening can lead to a catastrophic brittle failure in the form of plate or sheet peeling in the absence of end sheet anchorages [7], [14] and [15]. The ratio of the length of bonded plate within the shear span of the beam to the length of shear span has been considered as a parameter affecting the plate anchorage of strengthened RC beams with CFRP plates [16]. Some researchers have recommended that, to prevent a catastrophic brittle failure mode of strengthened beams by strip detachment, mechanical anchorage should be provided at the strip ends [13]. It seems that plate or sheet end anchorages have a greater effect in beams that are shorter, with a high ratio of shear force to bending moment, than in longer beams. To the best of our knowledge in the literature, anchorage is usually provided by anchor steel bolts, cover plates or FRP U-shaped external stirrups. Many researchers have proposed various FRP anchorage systems and tested them experimentally showing improvement in the behavior against the behavior of members strengthened with composites without anchorage [17-22]. Kalfat et al. [23] present the three main general categories of anchorage type which have been investigated to date to prevent debonding in $\mathrm{RC}$ members strengthened in flexure with FRP, namely (i) U-jacket anchors, (ii) Mechanically fastened metallic anchors and (iii) FRP anchors. The 
use of multiple small fasteners without any bonding, in opposite to large diameter bolts, distributes the load more evenly over the strip and reduces stress concentrations at the holes in the strip, which can lead to premature failure [24].

The aim of present paper is to investigate the use of Ustrips from FRPs combined with glass fibre tufts, as a composite anchorage system (CMAS), which can be applied easily at FRP ends to strengthen RC beams. The beneficial effects of this system are presented on the loading capacity as well as on the ductility of strengthened beams. Experimental results are obtained for five groups of RC beams strengthened with GFRP and CFRP bonded fabric, which are submitted to four- point bending. A single ply of a FRP fabric was bonded to the bottom of the beam with its strong direction being parallel to the longitudinal axis of the beam. In some groups of beams, FRP fabrics were anchored at their ends by single U-strips of GFRP or CFRP fabric. Specifically, Ustrips were bonded, in the form of external open stirrups at FRP ends. In some cases, two tufts of glass fibres were additionally used, as bolts of U-strips for the better anchorage of U-strips. Each of the tuft was then embedded, through the Ustrips at opposite face of the compression zone of beam web.

In the past years, several finite element analysis programs have been developed which include various constitutive models to predict the nonlinear response of concrete structures. The formulation of the concrete material models relies most of the times on a number of empirical parameters. Over the last years, researchers use these programs to predict the nonlinear response of concrete structures with adequate accuracy [25-30]. In the current study, experimental results were verified by theoretical and numerical analysis using ANSYS code [31]. The use of ANSYS for modelling of RC beams has been reported to be satisfactory by many researchers in the past [28, 32-37].

\section{EXPERIMENT}

\subsection{Specimens}

Five groups of specimens, each one of them including three $1100 \mathrm{~mm}$ long RC beams, with an effective span of $900 \mathrm{~mm}$, were designed, constructed in the Laboratory and tested under monotonic four-point bending loading [38]. The group of control beams (BV1) was designed to fail in flexure.

The cross section of the beams was $100 \mathrm{~mm}$ width and $150 \mathrm{~mm}$ depth, and the length of the beam tested was 1100 $\mathrm{mm}$. The dimensions of beams selected to be $\mathrm{b} / \mathrm{h} / \mathrm{l}=$ $100 / 150 / 1100 \mathrm{~mm}$ form the proportion $1: 1.5: 11$ and the beams in this way could be approximately considered as models of full-scale beams neglecting scaling effect phenomena. The longitudinal reinforcement was two rebars of 8 $\mathrm{mm}$ diameter nearby the bottom and two at the top of the beams. Since the beams are not so long and the shear span to effective depth ratio of beams was evaluated to be 2.22 , it is expected that control beams will fail in shear mode. However, this was avoided by reinforcing the beams with dense stirrups, $\varnothing 8 \mathrm{~mm}$ steel bars at $50 \mathrm{~mm}$ centres, at shear spans of length $300 \mathrm{~mm}$. At midspan of control beams closed stirrups of $8 \mathrm{~mm}$ diameter were sparsely used at $150 \mathrm{~mm}$ centres. The beams geometry and reinforcement details are shown in Fig. (1).

The groups of beams consisted of one with control beams, and four with beams strengthened with glass or carbon FRP bonded fabrics at their bottom face (Table 1). In two groups of the strengthened beams the FRP composites were anchored at their end. The position of the FRPs in the strengthened beams is shown in Fig. (2).

The group of control beams (BV1) was designed to fail in flexure. Beam groups B1/GFRP and B1/CFRP were strengthened with a glass and a carbon fabric bonded at the bottom face of the beam, respectively. A thin $(2 \mathrm{~mm})$ layer of two-component epoxy mixture was spread, by a paintbrush, over the entire bond area of beam bottom face prior bonding the fabric. In beam groups B1/GFRP/CMAS and B1/CFRP/CMAS one U-shaped strip of the same FRP as the strengthening fabric was bonded transversely at each end of the FRP. Through these strips, a tuft of glass fibres, the (CMAS) anchorage, saturated in the epoxy resin mixture was inserted in drilled holes at every face of the beam and the (CMAS)' protruding tips were then splayed circularly over the U-strip. Finally, the anchored U-strip was covered by a 100x100 mm patch of the same FRP. The fibres of the patch were placed perpendicular to the fibres direction of U-strip to improve the effectiveness of anchorage system (Fig. 2). More details about the experiments and the specimens are presented by Demakos [38]. In Table 1 all beams evaluated in this study are shown.

\subsection{Material Properties}

The concrete beams were casted to attain a 28-day concrete cube strength of about $20 \mathrm{MPa}$, whereas uniaxial tensile tests made on the rebars showed a Young's modulus of

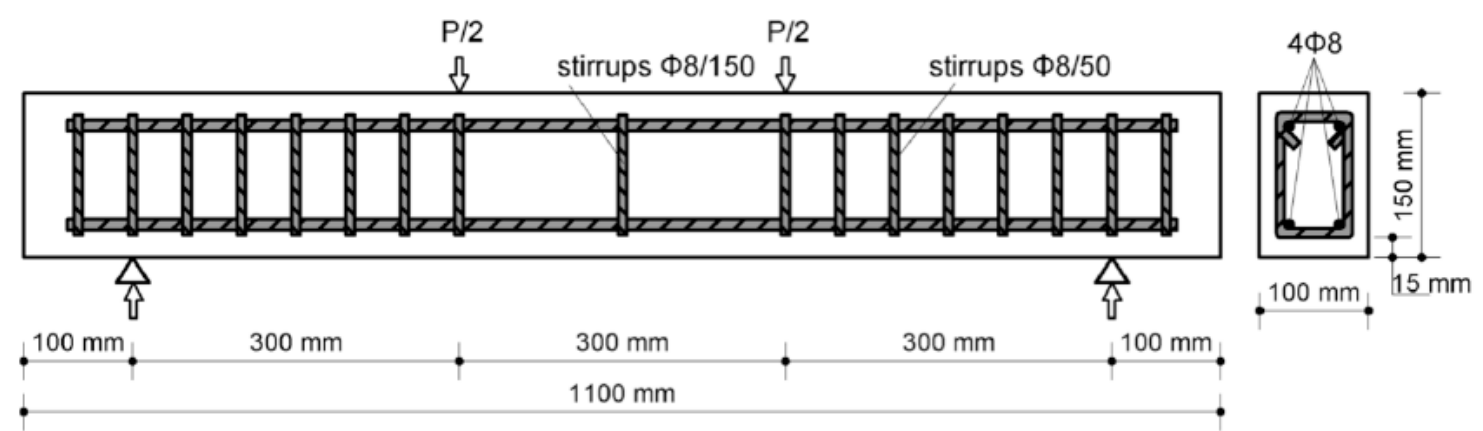

Fig. (1). Loading and geometry details of RC control beams (BV1). 
Table 1. Summary of Beams Tested in the Present Study

\begin{tabular}{|c|c|c|c|c|c|}
\hline Beam & \# of rebars & $\begin{array}{c}\text { Stirrups } \\
\text { (at shear spans) }\end{array}$ & $\begin{array}{c}\text { External } \\
\text { reinforcement }\end{array}$ & $\begin{array}{c}\text { FRP thickness } \\
{[\mathrm{mm}]}\end{array}$ & FRP end-anchorage \\
\hline BV1 & 4 & $8 \mathrm{~mm}$ at $50 \mathrm{~mm}$ centres & - & - & - \\
\hline B1/GFRP & 4 & $8 \mathrm{~mm}$ at $50 \mathrm{~mm}$ centres & One GFRP sheet & 1.30 & - \\
\hline B1/CFRP & 4 & $8 \mathrm{~mm}$ at $50 \mathrm{~mm}$ centres & One CFRP sheet & 0.45 & - \\
\hline B1/GFRP/CMAS & 4 & $8 \mathrm{~mm}$ at $50 \mathrm{~mm}$ centres & One GFRP sheet & 1.30 & $\begin{array}{l}\text { GFRP U-strips (400mm long, extended } \\
\text { to compression region) }\end{array}$ \\
\hline B1/CFRP/CMAS & 4 & $8 \mathrm{~mm}$ at $50 \mathrm{~mm}$ centres & One CFRP sheet & 0.45 & $\begin{array}{l}\text { CFRP U-strips (400mm long, extended } \\
\text { to compression region) }\end{array}$ \\
\hline
\end{tabular}

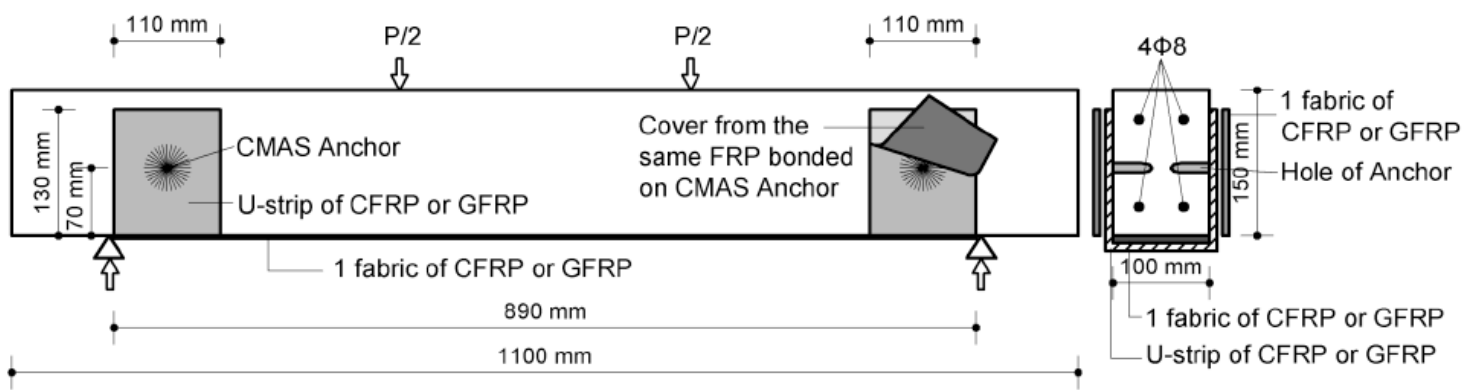

Fig. (2). Details of the composite material anchorage system (CMAS) used with FRPs in strengthened RC beams.

$204 \mathrm{GPa}$ and a high yield stress of $550 \mathrm{MPa}$. The woven fabric consisted of continuous fibres with the strongest direction of material oriented along the beam longitudinal axis, whereas the U-strip fibres were aligned along the beam lateral direction. The manufacturer specified the mechanical properties of all FRPs (GFRP and CFRP Composite) as listed in Table 2 . The adhesive epoxy mixture used for bonding the fabrics had the elastic properties listed in Table 3.

Table 2. Mechanical Properties of Fabrics

\begin{tabular}{|c|c|c|}
\hline Property & $\begin{array}{c}\text { GFRP } \\
\text { Composite }\end{array}$ & $\begin{array}{c}\text { CFRP } \\
\text { Composite }\end{array}$ \\
\hline \hline $\begin{array}{c}\text { Ultimate tensile strength in primary } \\
\text { fibre direction (MPa) }\end{array}$ & 550 & 1100 \\
\hline Elongation at break (\%) & 2 & 1.5 \\
\hline Tensile modulus (GPa) & 27.5 & 75 \\
\hline Laminate thickness (mm) & 1.3 & 0.45 \\
\hline
\end{tabular}

\subsection{Experimental Setup}

The beams were simply supported over an effective span of $900 \mathrm{~mm}$ and subjected to a monotonic four-point bending loading (Fig. 1). The loading was applied stepwise through a $200 \mathrm{KN}$ capacity servo-hydraulic machine in a forcecontrolled mode at the centre of a stiffened spreader trapezoidal beam, which in turn distributed the load equally on a couple of identical bearing pads placed on the top of the beams.
Table 3. Properties of Adhesives

\begin{tabular}{|c|c|}
\hline Property & Epoxy Mixture \\
\hline \hline Flexural strength (MPa) & 123.4 \\
\hline Flexural modulus (GPa) & 3.12 \\
\hline Tensile strength (MPa) & 72.4 \\
\hline Tensile modulus (GPa) & 3.18 \\
\hline Elongation (\%) & 5.0 \\
\hline
\end{tabular}

\section{NUMERICAL MODELLING WITH ANSYS}

ANSYS [31] finite element program was chosen for the numerical evaluation of RC beams strengthened with FRP composites. Concrete is a material presenting nonlinear behavior during loading and it was modelled with ANSYS to show similar behavior.

\subsection{Concrete}

Solid65 element was used to model the concrete. This element is used for the 3-D modelling of solids with or without reinforcing bars (rebar). The solid is capable of cracking in tension and crushing in compression. The William and Warnke [39] failure criterion is used for both cracking and crushing failure modes through a smeared model.

The element is defined by eight nodes and the isotropic material properties. Each node has three degrees of freedom, translations in the nodal $\mathrm{x}, \mathrm{y}$, and $\mathrm{z}$ directions. Up to three different rebar specifications may be defined. In our study reinforcement was modelled as another element. 
Shear transfer coefficient represents conditions of the crack face. This coefficient represents a shear strength reduction factor for those subsequent loads, which induce sliding (shear) across the crack face. A value $\beta_{\mathrm{t}}$ for an open crack and $\beta_{\mathrm{c}}$ for a closed crack are given. The value of shear transfer coefficient ranges from 0.0 to 1.0. A value of 0.0 represents a smooth crack with complete loss of shear transfer, while 1.0 represents a rough crack with no loss of shear transfer. The values used in many studies varied. Santhakumar et al. [35] for beams under pure bending used a value of 0.2 for open crack and 0.22 for closed crack, as proposed by Kachlakev et al. [33], while for beams under combined bending and torsion used values of 0.1 and 0.12 . Cotsovos et al. [28] studied the effect of this parameter and concluded that adopting relatively high values, the FEA model yield realistic predictions of the response of the ductile beam investigated in their study, while adopting the same parameters to a brittle beam the FEA model overestimated the load carrying capacity and the maximum deflection. In this study a range of values for these coefficients were tested and finally an open shear transfer coefficient of 0.25 and a closed shear transfer coefficient of 0.65 were chosen. Another parameter is the tensile crack factor, which is a multiplier for amount of tensile stress relaxation, and a value of 0.6 was adopted. The crushing capability was suppressed in this study and material cracked whenever a principal stress component exceeded the tensile stress, which was taken $1.9 \mathrm{MPa}$.

\subsection{Reinforcing Steel}

Barbosa and Riberio [32] modelled the same beam using Solid65 element for concrete, once adopting truss bars as discrete reinforcement connecting solid elements nodes and once composed uniquely of solid elements, some of which containing a smeared reinforcement. The results of loaddeflection curves were similar. In the present paper a Link180 element was used to model steel reinforcement. This 3-D spar element is a uniaxial tension-compression element with three degrees of freedom at each node, translations in the nodal $\mathrm{x}, \mathrm{y}$, and $\mathrm{z}$ directions. Reinforcement bars were modelled connecting the nodes of concrete solid elements. As concrete and reinforcement bars used the same nodes, a perfect bond was considered between these two materials. This assumption was followed by other researchers too [33-35].

\subsection{Steel Plates}

Steel plates were present at the supports and loading locations to avoid stress concentration problems. These plates were assumed to be of linear elastic material. An eight-node solid element, Solid45, was used to model the steel plates. The element is defined with eight nodes having three degrees of freedom at each node, translations in the nodal $\mathrm{x}, \mathrm{y}$, and $\mathrm{z}$ directions.

\subsection{FRP Laminates}

FRP materials consist of a large number of small, continuous, directionalized, organic (composite) fibres with advanced characteristics, embedded in a resin matrix. Depending on the type of fibre they are referred to as AFRP (aramid fibre based), CFRP (carbon fibre based) or GFRP (glass fibre based). In this paper the beams were strengthened with GFRPs and CFRPs at their bottom face.

A Shell43 element was used to model the FRP composites. The element has six degrees of freedom at each node. The bond between the FRP composites and concrete was considered also to be perfect.

\section{NUMERICAL ANALYSIS}

The stress-strain relation shown in Fig. (3a) is used for concrete. Young's modulus of elasticity is taken $27.6 \mathrm{GPa}$ and Poisson's ratio 0.2. Maximum stress value is assumed to be $24 \mathrm{MPa}$, near the mean value of the test results. In the ascending part of the curve, values are calculated from the formula presented by EC2 [40]. The strain corresponding to the maximum stress is assumed to be 0.002 . After the peakstress value there is a descending (strain-softening) branch until the ultimate strain of 0.0035 . Beyond this value, the stress values decrease linearly until a small residual value is attained and remains constant thereafter. The maximum tensile stress of concrete is set to a value of 1.9 MPa.

The stress-strain curve for steel rebars is shown in Fig. (3b) and it is identical in tension and compression. Young's modulus is taken $200 \mathrm{GPa}$ and Poisson's ratio 0.3. Yield stress of the rebars is $550 \mathrm{MPa}$, and ultimate stress $610 \mathrm{MPa}$, as they were obtained from the experimental results. Steel plates for supports and loading locations have a Young's modulus of $200 \mathrm{GPa}$ and Poisson's ratio of 0.3.

In the present study linear elastic properties of FRP composites are assumed, as shown in Fig. (3). The material properties for FRP composites used in analysis of the strengthened beams are shown in Table 2. Ultimate tensile strength in primary fibre direction was taken as $550 \mathrm{MPa}$ and 1100 MPa for GRFP and CFRP, respectively. Elongation at break is $2 \%$ and $1.5 \%$, tensile modulus is 27.5 and $75 \mathrm{GPa}$ for GRFP and CFRP, respectively. Laminate thickness is 1.3 $\mathrm{mm}$ for GFRP and $0.45 \mathrm{~mm}$ for CFRP. The stress-strain curves for GFRP and CFRP are shown in Fig. (3c) and (3d), respectively.

The beams were analyzed using ANSYS finite element model and compared with the test results of the above specimens. As it is presented below, in the experimental results it was shown that U-strip with (CMAS) anchorage improved the load capacity and ductility of RC specimens.

In analysis only one quarter of each beam was modelled due to transversal and longitudinal symmetry of the concrete beam and symmetry of loading applied. With this approach the computational time and computer disk space requirements were reduced significantly. The finite element mesh, loading regions of the beams and the boundary conditions are shown in Fig. (4). FRP composites are modelled in the bottom face of the beam. Steel reinforcement and stirrups modelling of beams is shown in Fig. (5).

\section{RESULTS}

Experimental results are presented below. In order to verify the experimental results, these are also compared with theoretical and numerical ones. 


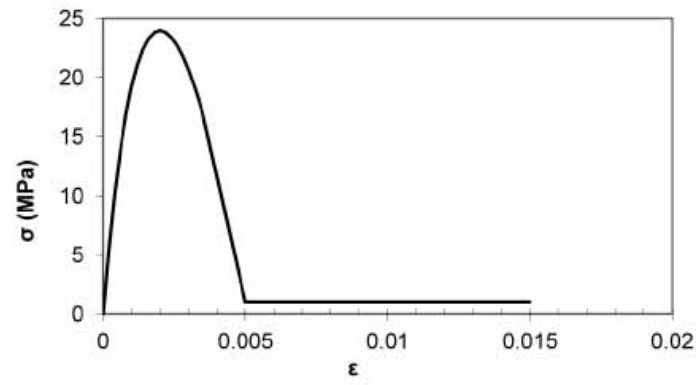

(a) Typical uniaxial compression stress-strain curve of concrete

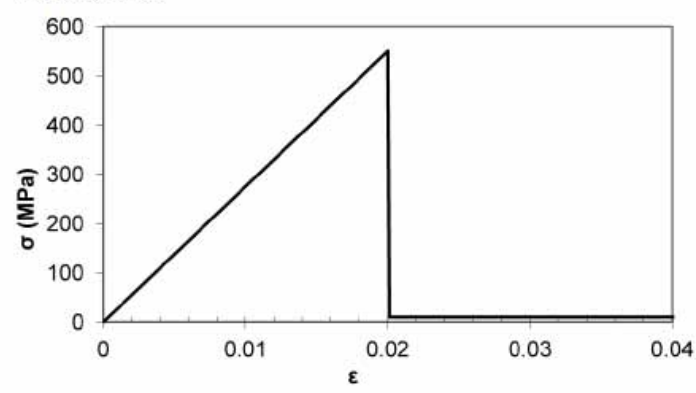

(c) Typical uniaxial tension stress-strain curve of GFRP in the direction of the fibres

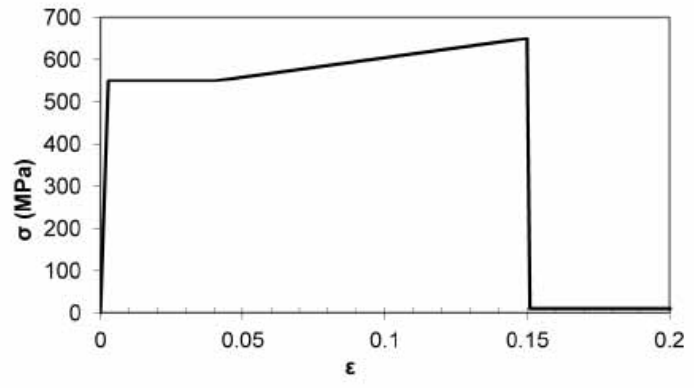

(b) Typical uniaxial stress-strain curve of steel

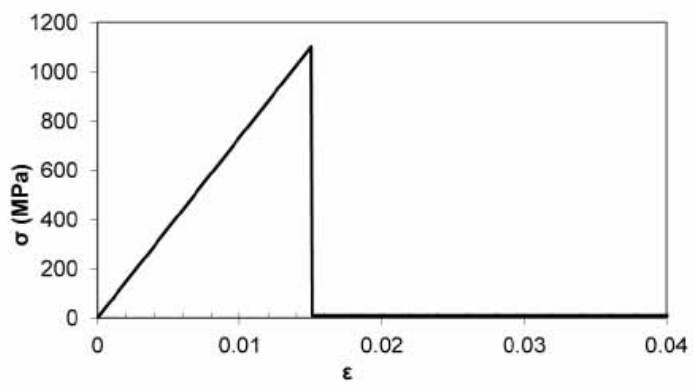

(d) Typical uniaxial tension stress-strain curve of CFRP in the direction of the fibres

Fig. (3). Material modelling behaviour with ANSYS [31].

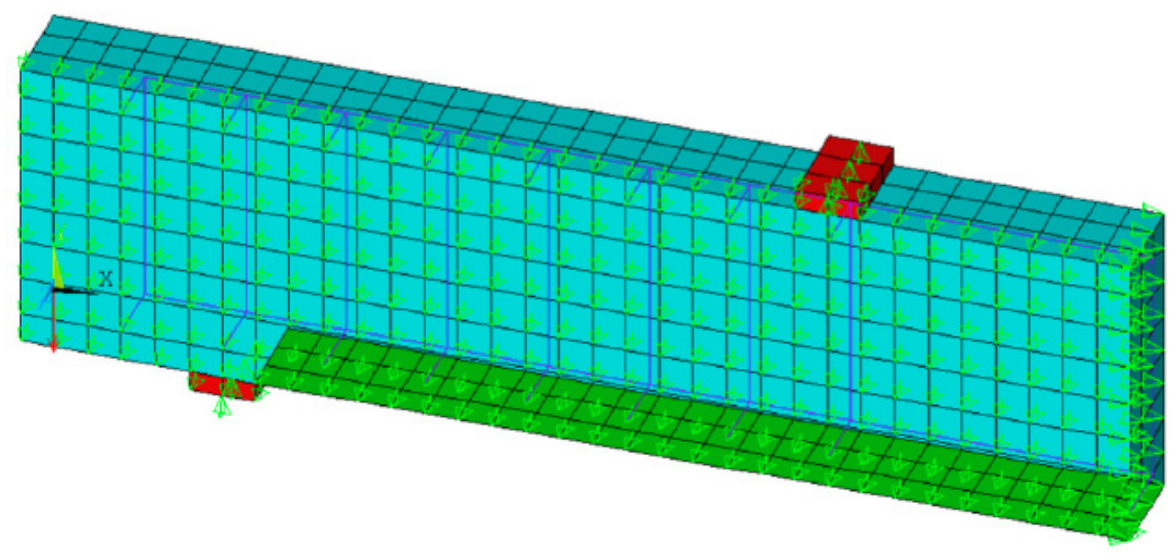

Fig. (4). Finite element mesh, boundary condition and loading regions for a quarter beam model.

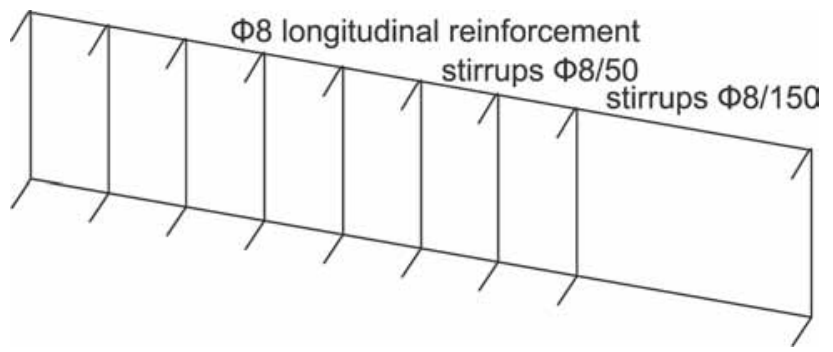

Fig. (5). Steel reinforcement and stirrups modelling of beams.

The groups of beams strengthened with FRPs are shown above in Table 1. Typical variations of measured load vs. deflection at mid-span of control as well as beams strengthened with FRPs are shown in Fig. (6) and the comparative results are presented in Table 4.
The group, BV1, of control beams behaved like a typical under-reinforced beam characterized by a ductile flexural response. The first cracks in these beams were appeared at a loading value of about 7.5 KN. Thereafter, the crack pattern became dense and their width increased steadily. The shape of the load-deflection curve indicates a loss of stiffness at a loading level of approximately $45 \mathrm{KN}$, due to yielding initiation of tensile reinforcement, which appeared at a deflection of $4 \mathrm{~mm}$. Afterwards large flexural cracks opened, the ultimate collapse of beams occurred at a loading level of $52 \mathrm{KN}$ by concrete crushing.

\subsection{Strengthening RC Beams with FRPs Only (Without any Anchorage)}

Generally speaking, the strengthened RC beams were stiffer, less ductile and attained higher ultimate load than the 


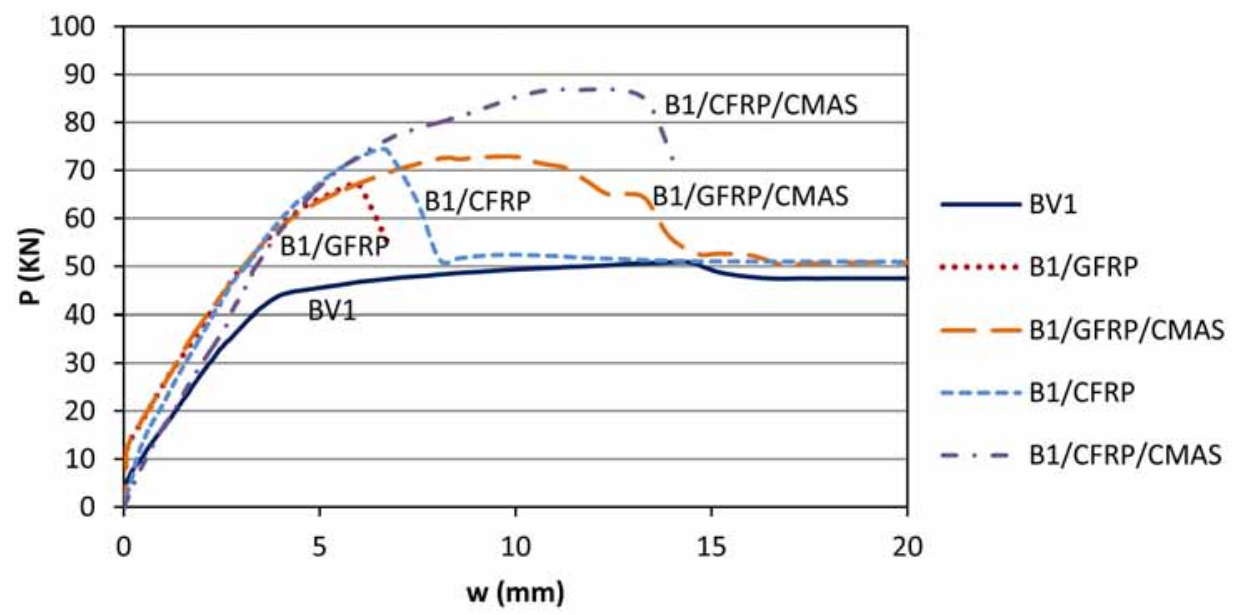

Fig. (6). Load-deflection curves for all beams tested.

Table 4. Cracking, Tension Steel Yielding, Ultimate Load and Corresponding Deflections and Strains of Beams Strengthened with FRP.

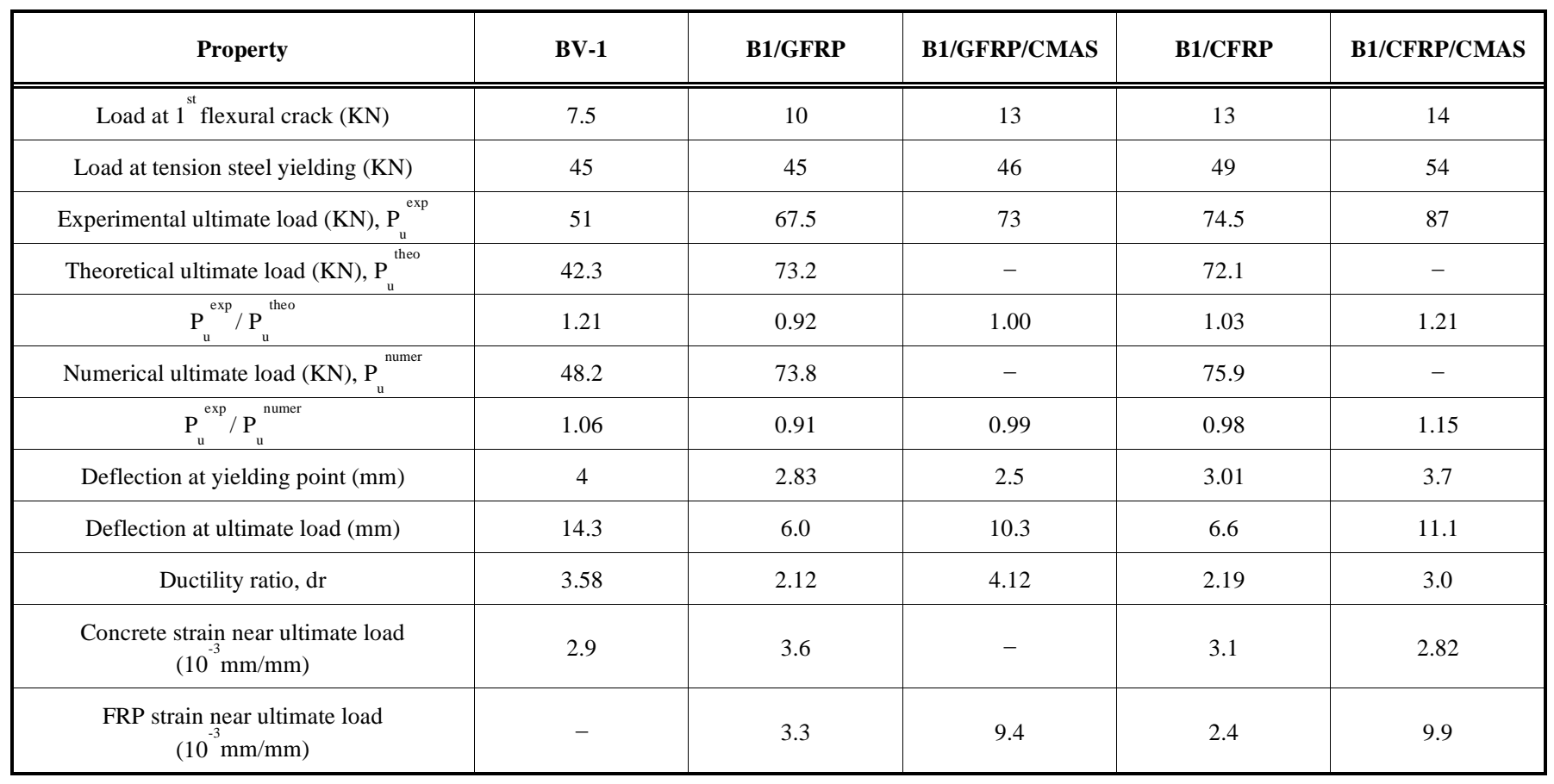

control specimens. The first crack in strengthened beams with one GFRP (B1/GFRP) or CFRP (B1/CFRP) fabric appeared at a loading value of 10 and $13 \mathrm{KN}$, respectively.

In both groups of these strengthened beams, their stiffness was affected by the normalized axial stiffness of FRPs, which was expressed by the product $t_{\mathrm{f}} \cdot E_{\mathrm{f}}$, where $t_{\mathrm{f}}$ and $E_{\mathrm{f}}$ denotes the thickness and tensile elastic modulus of the fabric used. Indeed, the stiffness of strengthened beams at their linear elastic deformation state was almost similar for both types of strengthened beams, as is shown by the slope of curves illustrated in Fig. (6). This is theoretically verified by evaluating the axial stiffness of both fabrics used, which was found to be about the same and equal to $35 \mathrm{MN} / \mathrm{m}$ :

Glass FRP: $t_{l} \cdot E_{l}=1.30 \mathrm{~mm} \cdot 27.5 \mathrm{GPa}=35.75 \mathrm{MN} / \mathrm{m}$
Carbon FRP: $t_{2} \cdot E_{2}=0.45 \mathrm{~mm} \cdot 75.0 \mathrm{GPa}=33.75 \mathrm{MN} / \mathrm{m}$

Although the stiffness of the strengthened beams B1/CFRP and B1/GFRP was similar and slightly higher than that of the control beams (Fig. 6), the ultimate loading of beams strengthened by a sheet of CFRP reached the value of 74.5 KN, which was considerably higher than the corresponding load of $67.5 \mathrm{KN}$ developed in beams strengthened by a sheet of GFRP.

To verify theoretically the experimentally obtained ultimate strength of beams, a method was applied for predicting the flexural response of strengthened RC beams, which was based on a linear distribution of strain through the depth of the section (Fig. 7). It was assumed that plane sections remain plane after bending and a perfect bond developed between external reinforcement and the concrete phase. 


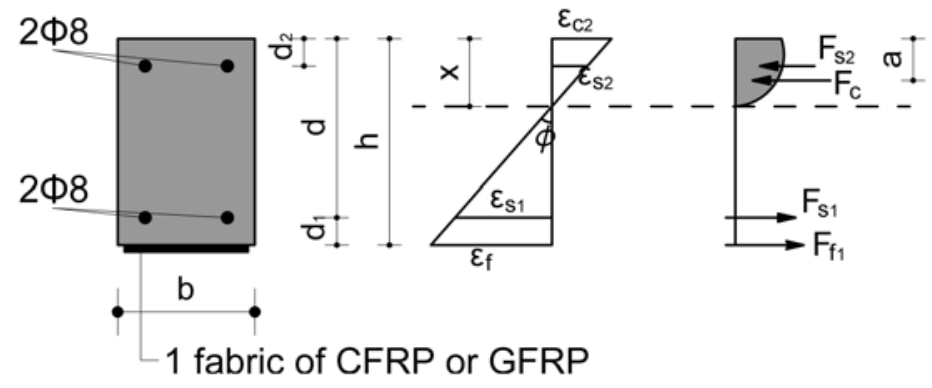

Fig. (7). Distribution of strain and stress through the depth of the section.

Material properties were assumed as previously mentioned in numerical analysis. It was also assumed that the tensile strength of concrete after cracking was zero and then the load-carrying capacity of the adhesive was ignored. In the calculations done, the behavior of the steel reinforcement was assumed to be elastic-perfectly plastic. Using this method of analysis, the theoretical ultimate loading for the control beam and a strengthened beam with one CFRP or one GFRP fabric was evaluated to be $42.3 \mathrm{KN}, 72.0 \mathrm{KN}$ or $73.2 \mathrm{KN}$, respectively.

Inspecting values of load in Table $\mathbf{4}$, it seems that the experimental peak loadings were close to the theoretical ones derived for similarly strengthened beams. However, the sudden decrease of ultimate capacity at relatively small deflection levels demonstrated that FRP strengthening without using an anchoring system resulted in sudden degradation of the beam structural behavior. Thus, adequate anchorage (CMAS) provided at the sheet ends could probably improve the beam's flexural response including its ductility levels. Beams strengthened with FRPs without anchorage initially presented dense flexural crack pattern at area of mid-span for loading level of about $50 \mathrm{KN}$ and then a flexural-shear type crack propagation occurred at the ends of FRPs. Finally, the failure mode of these beams was followed by peeling of the concrete cover along rebars, which shows that sufficient adhesion was developed between the laminate and the concrete cover at the beam bottom. Nevertheless, the observed failure modes resulted in early degradation of the load carrying mechanism. The ductility in these strengthened beams was about 55\% lower compared to that of control beams, as was evaluated by the ductility ratio, $\mathrm{dr}$, which was defined by the deflection at ultimate loading to the deflection at yielding of beam (Table 4).

\subsection{Effect of CMAS Anchorage}

Groups of beams B1/GFRP/CMAS and B1/CFRP/CMAS were designed to further improve their strength by preventing, as much as possible, the delamination of the laminate from the concrete face. For this purpose, the CMAS anchorage system was chosen and applied (Fig. 8) in this study. The U-anchors used have a maximum length of $0.11 \mathrm{~m}$ (Fig. 2) from the free ends of a GFRP- and CFRP- fabric as well, which was evaluated by the formula $1_{\max }(\mathrm{mm})=0.7\left(E_{f} \cdot t_{f} /\right.$ $\left.f_{c t m}\right)^{0.5}$, where $E_{f}(\mathrm{MPa})$ and $t_{f}(\mathrm{~mm})$ are the elastic modulus and thickness of FRP, respectively, and $f_{c t m}(\mathrm{MPa})$ is the concrete surface pull-off strength. In such a way the external reinforcement extends over a sufficient length for carrying safely the flexural moments designed to sustain the strengthened RC beam. By penetrating the U-jackets bonded at the FRP ends, a rounding tuft of glass fibres, CMAS, was embedded at each face of the beam core at a depth of about 60 mm (Fig. 2). The tuft was selected to be of glass fibres (Fig. 8), instead of carbon fibres, in order to be formed an as much as flexible anchorage at the ends of external reinforcement, which is necessary for the cooperation of the constituent phases during the deformation process of beams. The protruding tips of the anchorage fibres were splayed and bonded on the U-strips and then a patch of FRP covered the anchored U-strip (Fig. 2). Fig. (6) illustrates that a significant increase in the strength levels of beams strengthened with anchored FRPs was exhibited. Specifically, the ultimate loading of beams B1/GFRP/CMAS and B1/CFRP/CMAS was increased by $8.1 \%$ and $16.8 \%$, respectively, when compared to the respective loadings of the strengthened beams B1/GFRP and B1/CFRP without CMAS. This increase in the load capacity was also accompanied by a more ductile failure mode, as was shown by the higher deflections developed at mid-span of beams (Fig. 6). The cracks emanating from the tensile face of such beams propagate deeper at compression zone of their section in relation to the beams without CMAS. Furthermore, the extensive crack propagation from mid-span to the neighbourhood of U-strips at a flexural mode indicated the beneficial role of CMAS anchorage on the failure type of such strengthened beams. After the anchorage of FRPs failed, a cutting-off of fibre bolts from the beam web was accompanied by a consequent slip of the fabric from external composite U- strips and shear cracks developed mostly nearby the destroyed U-strips prior the final stage of beam collapse. To further clarify the effectiveness of CMAS anchorage, Table 4 provides a comparison of the structural response of (a) beams strengthened with FRPs and (b) beams strengthened with anchored FRPs. The results clearly show that an increase in the load carrying capacity occurred at an amount of about $8.1 \%$ and $16.8 \%$ for RC beams strengthened with one anchored GFRP or CFRP, respectively. Regarding the flexural rigidity of RC beams strengthened with anchored FRPs (Fig. 6), it does not substantially differ from the corresponding one of a beam strengthened with unanchored FRPs.

As concerns the ductility of beams, expressed by the ratio, dr, it seems that a significant increase of $94 \%$ or $37 \%$ occurred in beams with one anchored GFRP or CFRP fabric, respectively, in relation to corresponding values of ductility prevailed in RC beams strengthened without anchors. Finally, the complete utilization of the strength reserves 


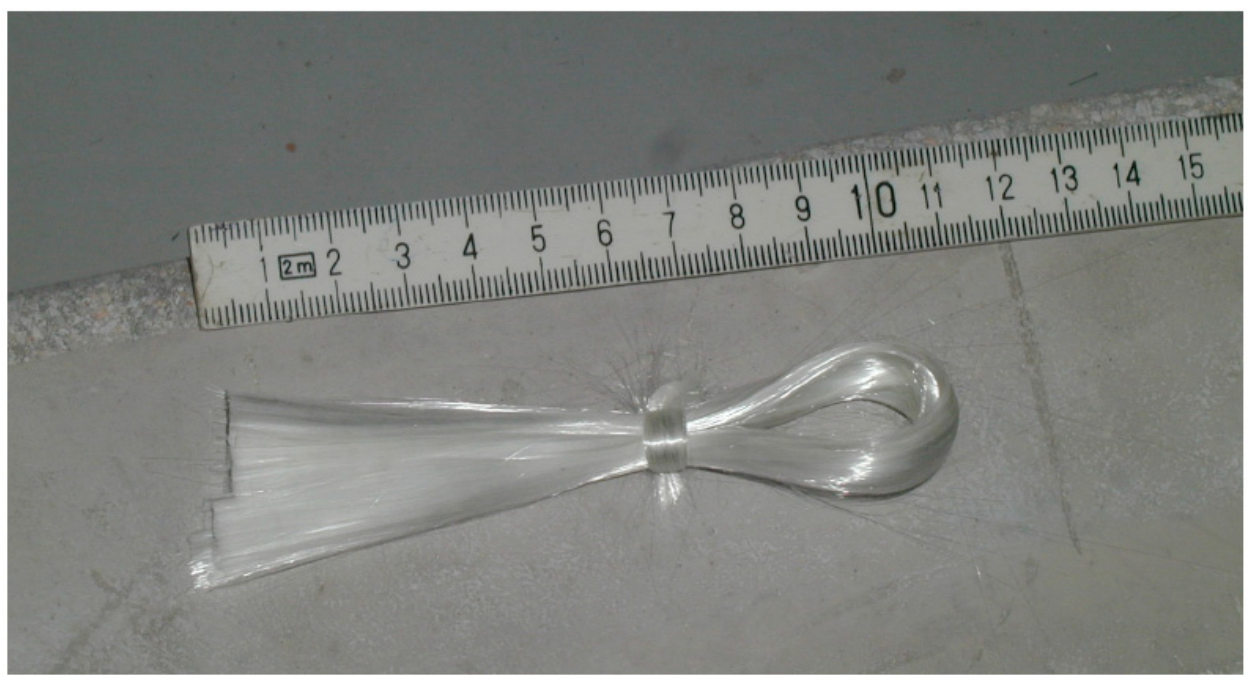

Fig. (8). Composite Material Anchorage System, CMAS, made from a tuft of glass fibres.

(over strength capability) of the FRP strengthening scheme and, thus, the effectiveness of proposed CMAS anchorage system seems valid, since the deformations measured at midpoint of GFRP and CFRP sheets approached the value of $1.0 \%$ (Table 4). The experimental peak loadings of 67.5 and $74.5 \mathrm{kN}$ measured for RC beams strengthened with unanchored GFRP and CFRP fabrics, respectively, varied slightly from the theoretically evaluated loadings of 73.2 and 72.1 $\mathrm{kN}$. Apart of possible small inaccuracies existing in tests, one can recognize that a stronger increase of ultimate loading occurred in RC beams strengthened with one anchored CFRP than in beams with one GFRP sheet (Table 4). Thus, the CMAS effectiveness is more pronounced in RC beams strengthened with CFRP fabric. The findings in this paper concerning the improvement of strength and increase of ductility in strengthened RC beams, due to applied CMAS anchorages on bonded FRPs, are in agreement with results reported in other studies, where RC beams have been strengthened with FRPs anchored by another way [13, 17, 41, 42]. Thus, the tests executed for this investigation demonstrated the beneficial role of anchoring the U-strips by glass fibre bolts especially on the noticeable increase of ductility levels of RC beams strengthened either with CFRP or GFRP fabrics. In addition, the experimentally obtained ultimate loading of RC beams strengthened with one fabric was found to approach the corresponding theoretically evaluated by EC2 [40] regulation.

\subsection{Numerical Verification}

The experimental load-deflection curves are compared with the ones obtained from numerical analyses in this study to validate the model. After the calibration of the model, it can then be used to extend the experimental results and study the behavior of other beams at much lower effort, cost and much quicker, without having to conduct many experimental tests.

The experimental and numerical load-deflection curves obtained for group of control beams, BV1, are shown in Fig. (9). The finite element model is slightly stiffer than the actual beam. This difference could have several explanations. The bond between steel reinforcement and concrete is assumed perfect, although in the actual beam slip of the reinforcement may occur. Micro defects are present to the concrete to some degree due to shrinkage and handling. Also, the real material properties may be slightly different during tests than the ones assumed in analyses. The failure load of the control beam is smaller than the experimental load by $5.5 \%$.

In Fig. (10) the experimental and numerical loaddeflection curves for the beam strengthened with glass FRP composites are shown. Both experimental beams, with and without the U-strip are compared with the analyzed beam, which has only a GFRP fabric at its bottom face, since bonding is assumed perfect in analyses. The numerical results are closer to the test results of the beam with the (CMAS) anchorage. The load-deflection curve is in good agreement and the numerical failure load is larger than the experimental by an amount of $1 \%$.

Fig. (11) illustrates the experimental and numerical loaddeflection curves for the beam strengthened with a carbon FRP composite. In this case the curve is in acceptable agreement and the failure load is $10 \%$ smaller than the beam with the CMAS anchorage.

Finally, in Fig. (12) the numerical load-deflection curves obtained for the beams B1/GFRP \& B1/CFRP strengthened with glass and carbon FRP are compared. The numerical curves concerning the ultimate loading and their initial slope are very close, unlike the experimental results. This was explained above since the FRP composites were chosen and evaluated to have similar axial stiffness being approximately $35 \mathrm{MN} / \mathrm{m}$.

A parametric study of models with different coefficients for concrete behavior did not increase significantly the accuracy of the results. The observed discrepancy may occur due to slight variations in the material properties taken in analysis and those attained in experiments. If more appropriate material properties are assigned in the model, the numerical study can be used to predict more precisely the behavior of strengthened beams with FRP laminates. Bonding between rebars and concrete or FRPs and concrete may be modelled to get better results. 


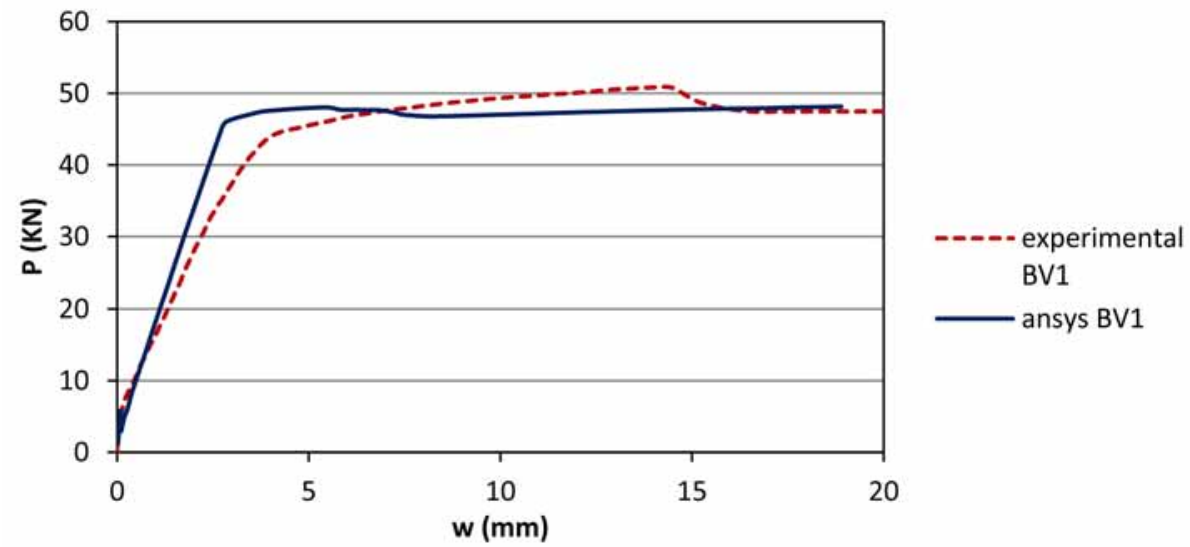

Fig. (9). Load - deflection curve for, BV1, control beams.

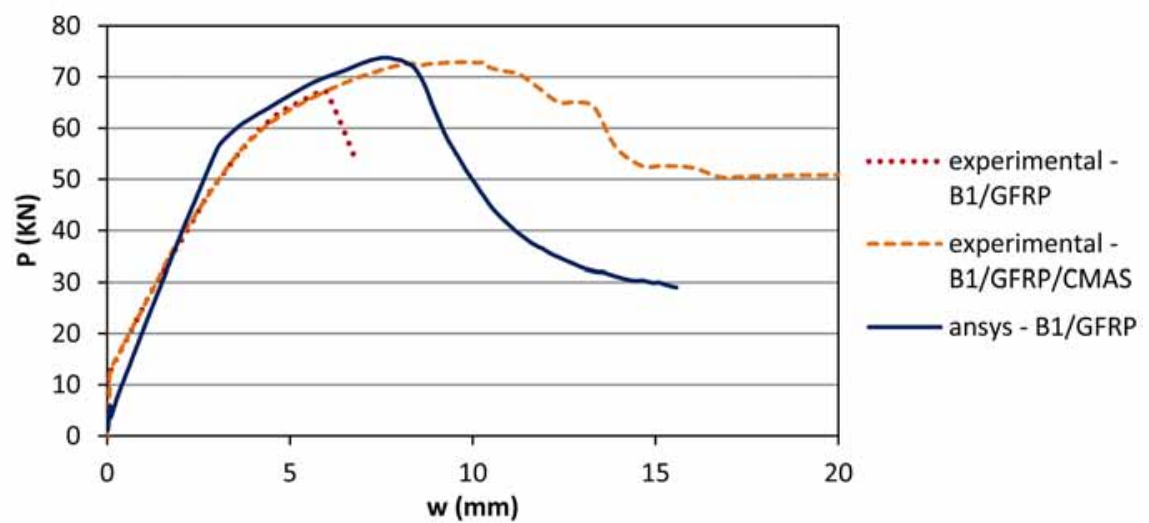

Fig. (10). Load - deflection curve for B1/GFRP and B1/GFRP/CMAS strengthened beam.

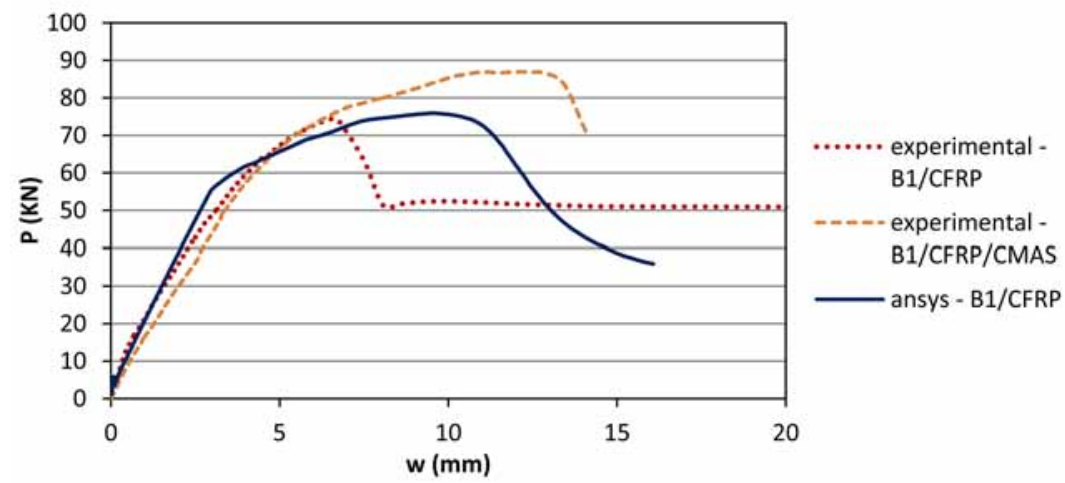

Fig. (11). Load - deflection curve for B1/CFRP and B1/CFRP/CMAS strengthened beam.

\subsection{Crack Pattern}

The crack pattern at each applied load step is monitored by ANSYS. In Fig. (13) the evolution of the crack pattern developed for the strengthened beam B1/GFRP is shown. Cracking is shown with a circle outline in the plane of the crack. Only the first crack at an integration point is shown. Finally, in Fig. (14) the crack pattern for B1/GFRP/CMAS tested beams are also shown. The crack patterns of the finite element models are similar with the experimental. Flexural cracks occurred in the mid span and were followed by diagonal shear cracks near the support. The failure modes of the finite element models show good agreement with the experimental.

\section{CONCLUSIONS}

The aim of the present paper is to investigate the influence of a composite anchorage at FRP sheet ends on optimizing the flexural response of a $\mathrm{RC}$ beam strengthened with 


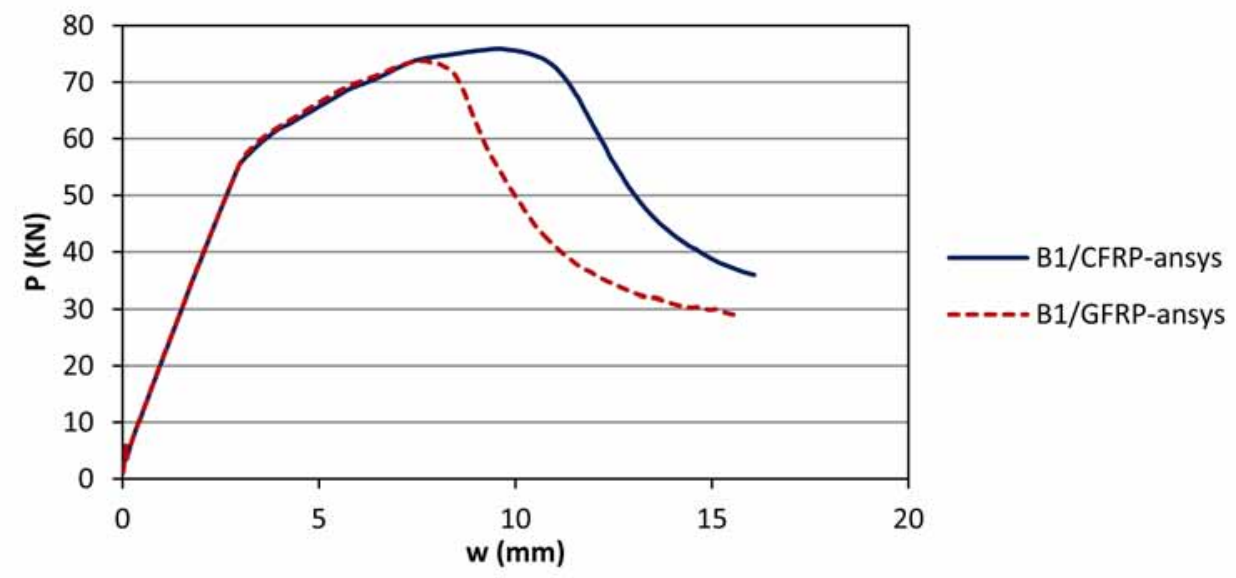

Fig. (12). Numerical load - deflection curve for beams B1/GFRP \& B1/CFRP.

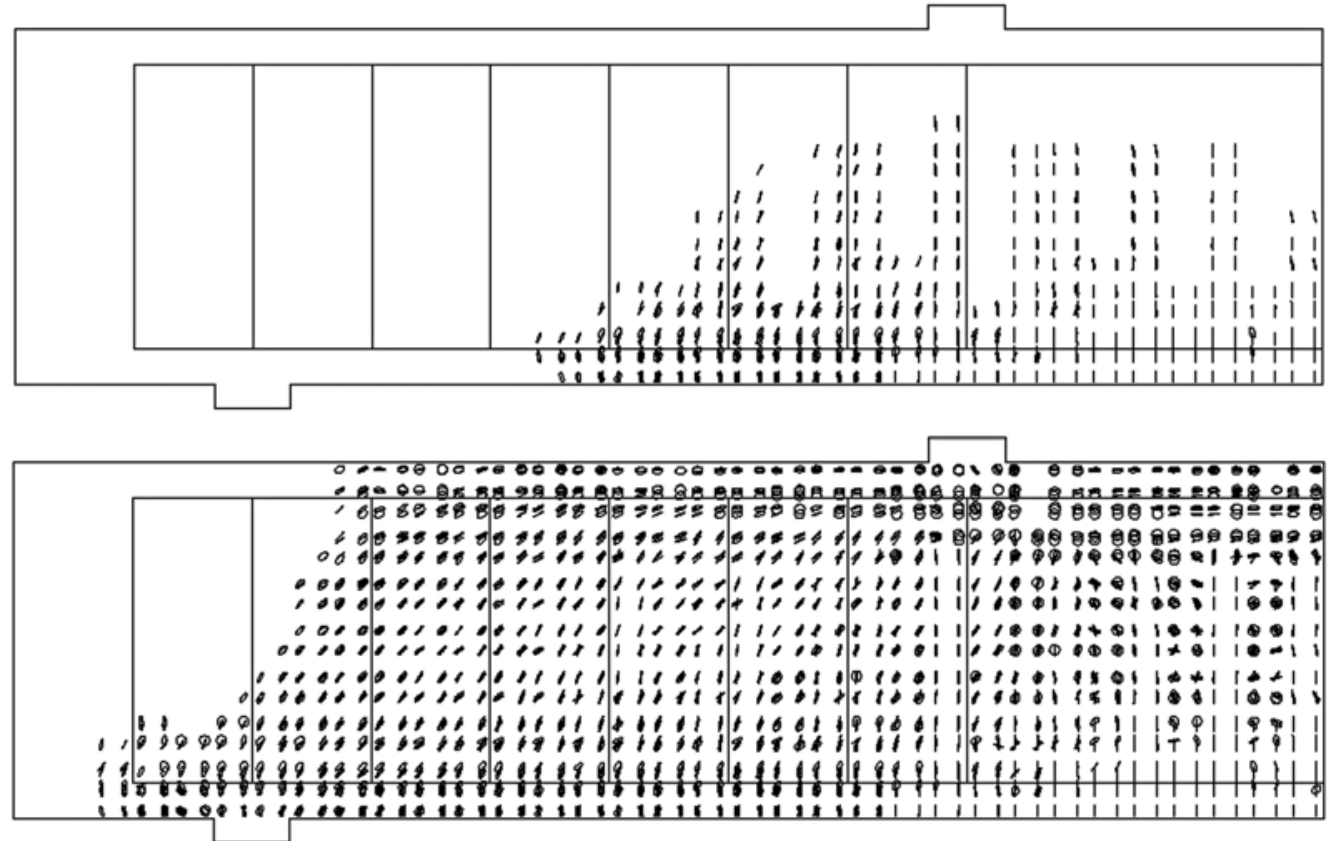

Fig. (13). Numerical evolution of crack pattern for, B1/GFRP, strengthened beam.

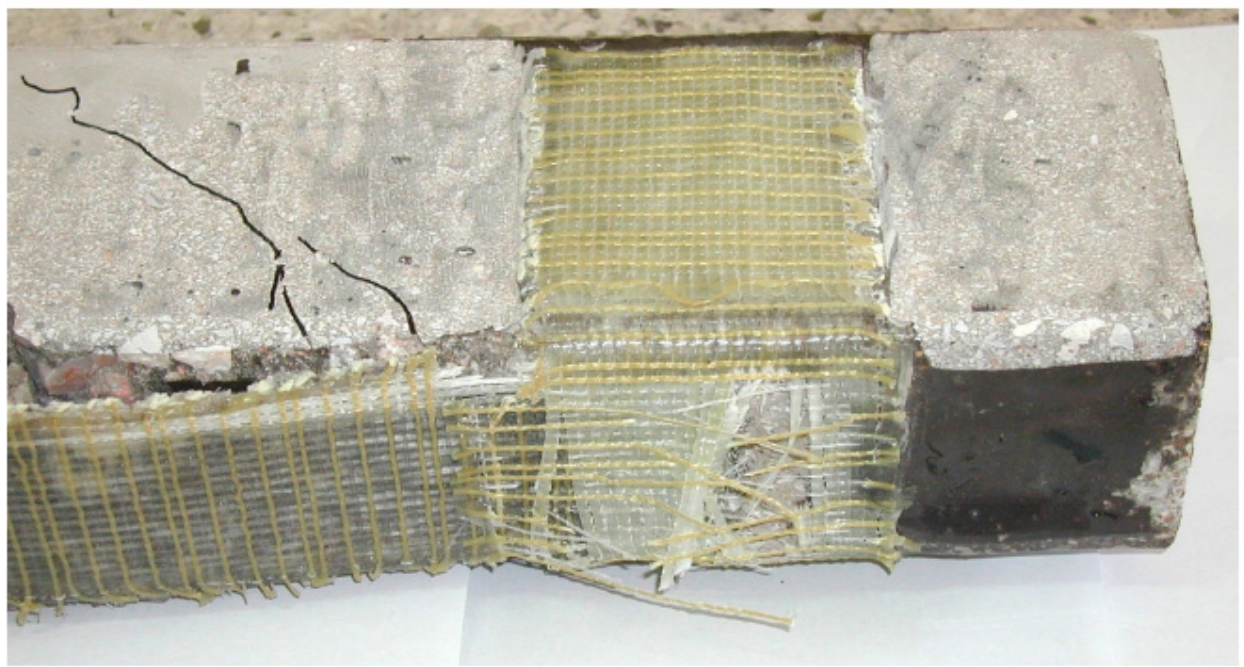

Fig. (14). Crack pattern of experimentally tested strengthened beams with an anchored GFRP (B1/GFRP/CMAS). 
composite laminates. Two different composite fabrics, namely a type of GFRP and CFRP sheet, were used as the main glass and carbon fibre external reinforcement. The fabrics were bonded with an epoxy mixture to the beam bottom. A composite material anchorage system, namely the CMAS system consisting of glass fibre bolts, was used to anchor, through bonded U-strips, the fabric in order to avoid premature detachment of it from the concrete. Generally speaking, $\mathrm{U}$-anchors resist the delamination stresses developed at fabric and act as external stirrups at their ends. These anchors impose on the external reinforcement to be in contact with concrete, avoiding thus its premature debonding from the beam section. Thus, an eventual sliding of the external reinforcement from U-jackets is delayed and the strengthened beams can sustain higher loads at increased ductility levels. The conclusions derived from this study can be summarized as follows:

1. Beams strengthened with one GFRP or CFRP fabric failed in brittle mode accompanied by concrete peeling along tension rebars and nearby the fabric ends, due to lack of FRP anchorage. Nevertheless, RC beams strengthened with one GFRP or CFRP fabric exhibited an increase of their ultimate strength by an amount of $30 \%$ and $43 \%$, respectively, in comparison to the strength attained from the control beams.

2. CMAS anchorage system was formed by U- shaped GFRP strips and a tuft of glass fibres at the ends of fabric. The application of this anchorage in $\mathrm{RC}$ beams strengthened with one GFRP or CFRP fabric resulted in an increase of the ultimate strength by an amount of $8 \%$ and $17 \%$, respectively, in relation to the respective strength attained from similar strengthened RC beams without anchorage. In addition, their stiffness was slightly enhanced, in comparison to that presented in control beams.

3. Glass U-strips in conjunction with CMAS anchorage system seem to provide a sufficient anchoring mechanism to prevent bonding slip between the fabric and the concrete substrate and induce a confinement of the external reinforcement, delaying thus the subsequent detachment of FRP from beam bottom face.

4. The experimental study carried out demonstrated that the brittle failure mode of beams strengthened with bonded composites without anchorage was improved to a ductile one when the composite laminates were applied on beams with composite anchorage (CMAS). Specifically, the ductility of RC beams strengthened with one anchored GFRP sheet approached that of the control beam.

5. Theoretical and numerical results are in good agreement with experimental results. The agreement between the experimental and numerical load-deflection curves as well as the failure modes and crack patterns, suggest that satisfactory prediction can be obtained with these models.

6. Numerical analyses can be used to simulate the behavior of reinforced concrete at lower cost and predict the failure process as the experimental results reveal. Nevertheless, experiments will always be necessary in obtaining information about the real behavior of reinforced con- crete and essential in order to verify the numerical models.

\section{CONFLICT OF INTEREST}

The author(s) confirm that this article content has no conflicts of interest.

\section{ACKNOWLEDGEMENT}

Declared none.

\section{REFERENCES}

[1] M. Baaza, M. Missihoun, and P. Labossiere, "Strengthening of reinforced concrete beams with CFRP sheets" in Proceedings of the $1^{\text {st }}$ International Conference on Composite In Infrastructure (ICCI '96), University of Arizona, Tucson, Arizona, 15-17 January 1996, pp. 746-759.

[2] J. Chajes, A. Thomson, F. Januszka, and W. Fin, "Flexural strengthening of concrete beams using externally bonded composite materials", Constructions and Building Materials, vol. 8, no. 3, pp. 191-201, 1994.

[3] M. Nakamura, H. Sakai, K. Yagi, and T. Tanaka, "Experimental studies on the flexural reinforcing effect of carbon fiber sheet bonded to reinforced concrete beam", in Proceedings of the $1^{\text {st }}$ International Conference on Composite in Infrastructure, (ICCI '96), University of Arizona, Tucson, Arizona, 15-17 January 1996, pp. 760-773.

[4] U. Meier, "Post strengthening by continuous fiber laminates in Europe", in Proceedings of the $3^{\text {rd }}$ International Symposium on Non-Metallic (FRP) Reinforcement for Concrete Structures (FRPRCS-3), Japan Concrete Institute, Sapporo, Japan, October 1997, pp. 41-56.

[5] C.C. Spyrakos, Ch.A. Maniatakis, E. Smyrou, and I.N. Psycharis, "FRP Strengthened Brick-Infilled RC Frames: An Approach for their Proper Consideration in Design", The Open Construction \& Building Technology Journal, vol. 6, Suppl 1-M19, pp. 306-324, 2012.

[6] C.C. Spyrakos, Ch.A. Maniatakis, I.N. Psycharis, E. Smyrou, and P.G. Asteris, "Validation of analytical models for the assessment of brick-infilled RC frames strengthened with FRPs", in Proceeding of COMPDYN 2013 4th ECCOMAS Thematic Conference on Computational Methods in Structural Dynamics and Earthquake Engineering, Kos Island, Greece, 12-14 June 2013.

[7] R. Hutchinson, and H. Rahimi, "Behavior of reinforced concrete beams with externally bonded fiber reinforced plastics", in Proceedings of the 5th International Conference on Structural Faults and Repair - 93, Engineering Technics Press, Edinburgh, U.K., 1993, pp. 221-228.

[8] T. Triantafillou, and N. Plevris, "Flexural behavior of concrete structures strengthened with epoxy-bonded fibre-reinforced plastics", in Proceedings of the International Seminar on Plate Bonding Technique, University of Sheffield, Sheffield, U.K., 1990.

[9] A. Wei, H. Saadatmanesh, and M. Eshani, "RC beams strengthened with FRP plates. II: Analysis and parametric study", ASCE Journal of Structural Engineering, vol. 117, no. 11, pp. 3434-3455, 1991.

[10] G. Camata, E. Spacone, and R. Zarnic, "Experimental and nonlinear finite element studies of RC beams strengthened with FRP plates", Composites Part B: Engineering, vol. 38, no. 2, pp. 277288, 2007.

[11] N. Attari, S. Amziane, and M. Chemrouk, "Flexural strengthening of concrete beams using CFRP, GFRP and hybrid FRP sheets", Construction and Building Materials, vol. 37, pp. 746-757, 2012.

[12] G. Li, A. Zhang, and Y. Guo, "Debonding-related strain limits for externally bonded FRP sheets in flexurally strengthened reinforced concrete beams", The Open Civil Engineering Journal, vol. 7, pp. 58-67, 2013.

[13] G. Spadea, F. Bencardino, and R. Swamy, "Structural behavior of composite RC beams with externally bonded CFRP", ASCE Journal of Composites for Construction, vol. 2, no. 3, pp. 132-137, 1998. 
[14] P. Ritchie, D. Thomas, L. Lu, and G. Connelly, "External reinforcement of concrete beams using fiber reinforced plastics", $A C I$ Structural Journal, vol. 88, no. 4, pp. 490-500, 1991.

[15] O. Ahmed, and D. Van Gemert, "Behavior of RC beams strengthened in bending by CFRP laminates", in Proceedings of the $8^{\text {th }}$ International Conference on Structural Faults and Repairs, Engineering Technics Press, Edinburgh, U.K., 1999.

[16] P. Fanning, and O. Kelly, "Smeared crack models of RC beams with externally bonded CFRP plates", Journal of Computational Mechanics, vol. 26, no. 4, pp. 325-332, 2000.

[17] C.B. Demakos, and G. Dimitrakis, "On the effect of FRP sheet composite anchorage to flexural behavior of reinforced concrete beams", in Proceedings of the conference Excellence in Concrete Construction through Innovation held at the Kingston University, United Kingdom, 9-10 September 2008.

[18] L.C. Bank, D.T. Borowicz, D. Arora, A.J. Lamanna, G.I. Velazquez, and J.C. Ray, "Strengthening of Concrete Beams with Fasteners and Composite Material Strips - Scaling and Anchorage Issues, Technical Report ERDC/GSL TR-04-5, US Army Corps of Engineers Engineer Research and Development Center, Washington, DC, 2004.

[19] H.W. Zhang, and S.T. Smith, "Influence of FRP anchor fan configuration and dowel angle on anchoring FRP plates", Composites Part B: Engineering, vol. 43, no. 8, pp. 3516-3527, 2012.

[20] S. Bae, and A. Belarbi, "Behavior of various anchorage systems used for shear strengthening of concrete structures with externally bonded FRP sheets", ASCE Journal of Bridge Engineering, vol. 18, no. 9, pp. 837-847, 2013.

[21] S. Qazi, L. Michel, and E. Ferrier, "Experimental investigation of CFRP anchorage systems used for strengthening RC joints", Composite Structures, vol. 99, pp. 453-461, 2013.

[22] G.C. Manos, M. Theofanous, and K. Katakalos, "Numerical simulation of the shear behaviour of reinforced concrete rectangular beam specimens with or without FRP-strip shear reinforcement", Advances in Engineering Software, vol. 67, pp. 47-56, 2014.

[23] R. Kalfat, R. Al-Mahaidi, and S. Smith, "Anchorage devices used to improve the performance of reinforced concrete beams retrofitted with FRP composites: state-of-the-art review", ASCE Journal of Composite Construction, vol. 17, no. 1, pp. 14-33, 2013.

[24] A. Lamanna, L. Bank, and D. Scott, "Flexural strengthening of reinforced concrete beams using fasteners and fiber-reinforced polymer strips", ACI Structural Journal, vol. 98, no. 3, pp. 368376, 2001.

[25] H.G. Kwak, and F.C. Filippou, "Finite element analysis of reinforced concrete structures under monotonic loads". Report No. UCB/SEMM-90/14, University of California, Berkeley, 1990.

[26] A. Mehrabi, and P. Shing, "Finite element modeling of masonryinfilled RC frames", ASCE Journal of Structural Engineering, vol. 123, no. 5, pp. 604-613, 1997.

[27] D.M. Cotsovos, and M.N. Pavlović, "Numerical investigation of concrete subjected to high rates of uniaxial tensile loading", International Journal of Impact Engineering, vol. 35, no. 5, pp. 319335, 2008.

[28] D.M. Cotsovos, C.A. Zeris, and A.A. Abbas, "Finite element modelling of structural concrete", in COMPDYN 2009, Proceedings of
ECCOMAS Thematic Conference on Computational Methods in Structural Dynamics and Earthquake Engineering, Rhodes, 2009.

[29] P.G. Asteris, and D.M. Cotsovos, "Numerical investigation of the effect of infill walls on the structural response of RC frames", The Open Construction \& Building Technology Journal, vol. 6, Suppl 1-M11, pp. 164-181, 2012.

[30] A.H. Khagehhosseini, R. Porhosseini, R. Morshed, and A.Eslami, "An experimental and numerical investigation on the effect of longitudinal reinforcements in torsional resistance of RC beams", Structural Engineering and Mechanics, vol. 47, no. 2, pp. 247-263, 2013.

[31] ANSYS Inc., ANSYS Release 11, User's Manual, 2006.

[32] A.F. Barbosa, and G.O. Ribeiro, "Analysis of Reinforced Concrete Structures Using Ansys Nonlinear Concrete Model”, in S. Idelsohn, E. Onate and E. Dvorkin (Eds.), Computational Mechanics: New Trends and Applications, Barcelona, Spain, 1998.

[33] D. Kachlakev, T. Miller, S. Yim, K. Chansawat, and T. Potisuk, "Finite Element Modeling of Reinforced Concrete Structures Strengthened with FRP Laminates", Report for Oregon Department of Transportation, Salem 2001.

[34] P. Fanning, "Nonlinear Models of reinforced and post-tensioned concrete beams", Electronic Journal of Structural Engineering, vol. 2, pp. 122-132, 2001. [Online] Available; http://www.ejse.org/Archives/Fulltext/200102/02/20010202.pdf [Accessed Jul. 05, 2013].

[35] R. Santhakumar, R. Dhanaraj, and E. Chandrasekaran, "Behaviour of retrofitted reinforced concrete beams under combined bending and torsion: A numerical study", Electronic Journal of Structural Engineering, vol. 7, pp. 34-45, 2007. [Online] Available; http://www.civenv.unimelb.edu.au/ejse/Archives/Fulltext/2007/Spe cial/200709.pdf [Accessed Jul. 05, 2013].

[36] M.C. Sundarraja, and S. Rajamohan, "Flexural strengthening effect on RC beams by bonded composite fabrics", Journal of Reinforced Plastics and Composites, vol. 27, no. 14, pp. 1497-1513, 2008.

[37] A.M. Ibrahim, and M.Sh. Mahmood, "Finite element modeling of reinforced concrete beams strengthened with FRP laminates", European Journal of Scientific Research, vol. 30, no. 4, pp. 526541, 2009.

[38] C.B. Demakos, "Investigating the Influence of FRP Sheet Anchorage to Structural Response of Reinforced Concrete Beams", in Proceedings of the International Scientific Conference SynEnergy Forum, Spetses, 2008.

[39] K.J. Willam, and E.D. Warnke, "Constitutive Model for the Triaxial Behavior of Concrete", in Proceedings of International Association for Bridge and Structural Engineering, 19, ISMES, Bergamo, Italy, pp. 174-186, 1975.

[40] EN 1992-1-1, Eurocode 2: Design of concrete structures. Part 1: General rules and rules for buildings 2004.

[41] G. Spadea, F. Bencardino, and R. Swamy, "Optimizing the performance characteristics of beams strengthened with bonded CFRP laminates", RILEM Material Structures, vol 33, no. 226, pp. 119226, 2000.

[42] G. Spadea, R. Swamy, and F. Bencardino, "Strength and Ductility of RC beams repaired with bonded CFRP laminates", Journal of Bridge Engineering, vol. 6, no. 5, pp. 349-355, 2001.

(c) Demakos et al.; Licensee Bentham Open.

This is an open access article licensed under the terms of the Creative Commons Attribution Non-Commercial License (http://creativecommons.org/licenses/by-nc/3.0/) which permits unrestricted, non-commercial use, distribution and reproduction in any medium, provided the work is properly cited. 